\title{
Agnosticismo, indiferencia y ateísmo según X. Zubiri ${ }^{1}$
}

\section{Hugo Gudiel, Centro de Reflexión Teológica, San Salvador.}

\section{Introducción}

En este trabajo concentramos nuestra atención, siguiendo a Xavier Zubiri, en tres actitudes fundamentales que a nuestro juicio caracterizan a muchos hombres y mujeres de hoy: el agnosticismo, la indiferencia y el ateísmo ${ }^{2}$. ¿Cómo exponer y justificar en modo radical y coherente tales actitudes, desde la perspectiva zubiriana de la voluntad de fundamentalidad? Es la pregunta que de algún modo orienta esta exposición.

El propósito de estas páginas es mostrar que aquéllas son actitudes básicas del ser humano en las que aparece un aspecto esencial de la voluntad de fundamentalidad: ya sea como voluntad de buscar, como voluntad de vivir o como voluntad de ser. Y, por lo mismo, también se pone de relieve en tales actitudes, un aspecto esencial no integrado de la dimensión humana de la fe. De alguna manera todo hombre tiene $\mathrm{fe}^{3}$.

1. En este artículo, sobre todo a partir de la segunda sección, seguimos muy de cerca algunas páginas del capítulo cuarto de nuestra tesis doctoral de teología, defendida en Roma en el mes de marzo del año 2006. Obviamente, hemos hecho algunos añadidos y ampliaciones de contenido en algunos momentos. También proponemos una reestructuración propia que responda a la problemática concreta planteada en la totalidad del artículo aquí expuesto, cfr. H. C. Gudiel García, La fe según Xavier Zubiri. Una aproximación al tema desde la perspectiva del problema teologal del hombre, Roma, 2006, pp. 152-166.

2. Dejamos de lado la actitud del teísta en la cual puede darse la unidad entre inteligencia y fe. Para ampliar este punto véase nuestro trabajo: H. C. Gudiel García, La fe según Xavier Zubiri, pp. 130-152.

3. Naturalmente, aquí no nos referimos a ningún tipo de fe religiosa, ni mucho menos a 
Justificar la fe en su dimensión humana no compete exclusivamente al teísta como erróneamente se piensa, y como falsa y, a veces, maliciosamente, pretenden algunos. Es también responsabilidad del agnóstico, del indiferente y del ateo dar razón de su fe. El agnosticismo, la indiferencia y el ateísmo son modos concretos de justificar la entrega. Ciertamente son modos que tienen sus propias características y limitaciones como tendremos que mostrar en la entera exposición. En los primeros aparece como suspensión de la fe; en los segundos se pone de manifiesto como entrega indiferente; $y$, en los terceros como fe en la pura facticidad. No cabe duda que éstos son, en definitiva, modos de fe (cfr. HD 295) ${ }^{4}$.

Este artículo comprende seis secciones. En primer lugar, proponemos brevemente unas cuantas nociones fundamentales para lograr una comprensión coherente del tema. En segundo lugar, planteamos en modo adecuado el problema. En tercer lugar, exponemos el primer hecho en el que se subraya la intelección, el agnosticismo y la voluntad de buscar. En cuarto lugar, mostramos el segundo hecho bajo el título de la indiferencia y la voluntad de vivir. En quinto lugar, examinamos la tercera actitud humana: el ateísmo y la voluntad de ser. Y, en sexto lugar, se recoge lo positivo encontrado en esos tres hechos bajo la síntesis: la "voluntad de ser viviendo en búsqueda" (HD 291).

\section{Algunas nociones fundamentales}

De ninguna manera pretendemos en esta sección exponer en toda su amplitud y complejidad las nociones aparecidas y utilizadas por Zubiri en este trabajo. Nuestro propósito consiste simplemente en poner de relieve un mínimo marco referencial a partir del cual puedan leerse y ubicarse las siguientes reflexiones del filósofo vasco.

la fe cristiana. En el sentido más lato de la expresión, aludimos a la fe en su dimensión humana y, por lo tanto, teologal. Desde una perspectiva propiamente filosófica esta dimensión humana de la fe aparece como fundamento de la dimensión religiosa y cristiana de la fe.

4. El problema de Dios, y por consiguiente el de su entrega, es una cuestión que compete a todo ser humano, sin excepción alguna. Por eso, Zubiri afirma que "lo fundamental es descubrir que Dios es problema para todos. El creyente tiene que dar razones de su creencia, y el ateo tiene que dar también las razones de su negación de Dios, así como tiene que dar también el agnóstico las razones de su agnosis. El ateísmo y el agnosticismo no son menos creencias que el teísmo. Los tres están necesitados de fundamentar su actitud porque no basta en última instancia con la firmeza de un estado de creencia sino que es necesaria su justificación intelectual" (HD 12). (Naturalmente, en este contexto no hay que olvidar la actitud concreta del despreocupado y del indiferente como veremos.)

El filósofo vasco es consciente de la radicalidad de esta cuestión, ya que el problema de Dios en cuanto problema "no es un problema arbitrariamente planteado por la curiosidad humana, sino que es la realidad humana misma en su constitutivo problematismo" (HD 13). 


\subsection{Inteligencia sentiente $y$ actualidad ${ }^{5}$}

Ante todo, cabe destacar que para nuestro autor la inteligencia humana es, en rigor, "inteligencia sentiente" ${ }^{\text {. }}$. Inteligir y sentir no son actos de dos facultades contrapuestas ( $c$ fr. IRE 19).

La inteligencia sentiente se refiere a un solo acto con dos momentos que ciertamente pueden diferenciarse, pero que jamás deben separarse: sentir e inteligir. E1 hombre intelige sintiendo y siente inteligiendo. No hay dualismo alguno en esta concepción de la inteligencia sentiente. Es aprehensión de realidad. Realidad es el "de suyo" de lo sentido: es "la formalidad de realidad" (IRE 57). Pues bien, formalidad de realidad es "formalidad del 'de suyo' como modo de quedar en la aprensión" (IRE 60).

La esencia formal de la intelección es la "actualidad"7. En efecto, Zubiri dice que la esencia de la actualidad radica en el "estar presente [de lo real] desde sí mismo por ser real" (IRE 139) ${ }^{8}$. Inteligir es, por tanto, la mera actualización de 1o real por el mero hecho de ser real en la inteligencia humana. Las nociones de

5. En este contexto puede ser útil la lectura de I. Ellacuría, "La nueva obra de Zubiri: "Inteligencia sentiente"”, en Razón y Fe 995 (1981) pp. 126-139; en concreto pueden verse las páginas 132-139 en donde Ellacuría señala la importancia de estas dos nociones de Zubiri: Inteligencia sentiente y actualidad. Véase también de I. Ellacuría, "Biología e inteligencia”, en Realitas III-IV, Madrid, 1979, pp. 281-335.

6. Como sabemos, la filosofía de la inteligencia o noología de Zubiri está contenida en su trilogía titulada Inteligencia sentiente (IRE, IL, IRA). En este trabajo es imposible presentar la totalidad de los conceptos expuestos en esos tres tomos. Sin embargo, a mi modo de ver las nociones de inteligencia sentiente, actualidad, sustantividad y verdad real son un punto de partida firme e inexorable para comprender el artículo que aquí presentamos. Véase también M. Mazón, Enfrentamiento y actualidad. La inteligencia en la Filosofía de Xavier Zubiri, Madrid, 1999, pp. 141-191; J. M. Millás, La realidad de Dios. Su justificación y sentido en Xavier Zubiri y Javier Montserrat, Roma-Madrid, 2004, pp. 13-23.

7. Un desarrollo básico de esta noción en IRE 133-169. Véase también, M. Mazón, Enfrentamiento y actualidad, pp. 193-264; J. M. Millás, “Zubiri y la Eucaristía. La aplicación de los conceptos de actualidad y sustantividad en la teología de la Eucaristía”, Gregorianum 81 (2000) 299-323, concretamente 263-269.

8. A mi juicio estamos ante una síntesis que presenta lo fundamental de la actualidad. La misma síntesis puede verse en IRE 144-145. Como muy bien afirma Ellacuría, "la actualidad es una categoría de extraordinaria importancia para resolver varios problemas filosóficos y teológicos, porque tiene la característica de ser algo plenamente real [...] La actualidad pertenece a la realidad misma de la cosa actual, pero no le añade, ni le quita, ni siquiera modifica formalmente ninguna de sus notas reales. Consiste en un estar presente desde si mismo, desde la propia realidad ante otras realidades y no exclusivamente ante la inteligencia. Consiste en el estar mismo de la presencia, y tiene por ello un estricto carácter físico, expresado en el 'estar' de la presencia", I. Ellacuría, "La nueva obra de Zubiri”, Razón y Fe 995 (1981) 137. 
inteligencia sentiente y actualidad ponen de manifiesto que la inteligencia sentiente es formalidad del "de suyo".

\subsection{Sustantividad y verdad real}

Pero el "de suyo" puede considerarse también desde el punto de vista de la sustantividad. Efectivamente, el "de suyo" es un momento constitutivo de la realidad. Es la "radicalidad de la cosa misma" en cuanto real (IRE 191). Por tanto, el "de suyo" no es tan sólo el modo como la cosa aprehendida nos es presente, sino que es por ello mismo el momento constitutivo de la realidad de ella en y por sí misma" (IRE 193). Y esta cosa real formalizada es lo real, es sustantivi$\mathrm{dad}^{9}$. Ahora bien, la sustantividad tiene ser. Es el ser de lo sustantivo ${ }^{10}$. Justo por eso la realidad es. El ser de lo sustantivo es, ante todo, actualidad "de lo real en el mundo" (IRE 219). El ser también es algo ulterior a la realidad, es la ulterio ridad del ser (IRE 221). Finalmente el ser es algo sentido, pero sentido en modo indirecto: es la oblicuidad del ser. Estos son los tres momentos estructurales del ser de lo sustantivo (IRE 224).

Recordemos que la intelección es mera actualización de lo real en la inteligencia humana. Ahora bien, la actualidad añade a lo real precisamente ese en la intelección (IRE 229) ${ }^{11}$. Se trata de una verdad primaria y radical que, en rigor, añade a la realidad esa "ratificación según la cual lo aprehendido como real está presente en su aprehensión misma: es justo ratificación del 'de suyo". Es lo que Zubiri llama verdad real (IRE 233) ${ }^{12}$. Pues bien, "lo real está 'en' la intelección, y este "en' es ratificación" (IRE 234). Las tres dimensiones de la realidad (to-

9. Sobre este término véase también J. M. Millás, "Zubiri y la Eucaristía. La aplicación de los conceptos de actualidad y sustantividad a la teología de la Eucaristía”, en Gregorianum 81 (2000) 269-277.

10. Un punto de partida fundamental para una adecuada comprensión de "el ser de lo sustantivo" desde Zubiri puede verse en IRE 217-228. Véase también, I. Ellacuría, "La idea de filosofia en Xavier Zubiri", en Homenaje a Xavier Zubiri I, Madrid, 1970, pp. 493-495.

11. Una iniciación adecuada a este tema en IRE 229-241.

12. La novedad y originalidad del filósofo vasco en este tema es clarificada por un conocedor suyo en los siguientes términos: "Nadie dudaría que en el tratamiento zubiriano de la verdad lo que el filósofo denomina 'verdad real' representa su contribución más importante y más original. Aunque en la primera exposición que el filósofo ofreció de este tema (1962) este punto no resultaba del todo claro, con posterioridad se ha ido viendo que la verdad real no tenía equivalente en los tratamientos tradicionales a los que los filósofos sometieron la verdad 'lógica', la verdad 'ontológica' e incluso la verdad 'óntica'. Era preciso todo el tratamiento que la aprehensión primordial de realidad estaba exigiendo para que se pudiese ver el lugar propio y el alcance exacto de la verdad real", A. Pintor-Ramos, Realidad y Verdad. Las bases de la filosofía de Zubiri, Salamanca, 1994, p. 123. 
talidad, coherencia y dureza) se ratifican en tres dimensiones de la verdad real (riqueza, "qué" de algo, y estabilidad), respectivamente. Y cada una de estas dimensiones de la verdad real se ratifica al mismo tiempo en tres modos de ratificación: manifestación, firmeza y constatación (cfr. IRE 239-241).

\subsection{Religación y voluntad de fundamentalidad}

Otro término básico que cabe destacar en este trabajo es el de religación ${ }^{13}$. Zubiri parte de una convicción muy suya: el hombre es sustantividad humana, y la esencia de ésta consiste en ser "animal de realidades" (HD 46). La formalidad de realidad está abierta y por eso el hombre es animal de realidades. La realidad humana es animal personal, pero también es realidad relativamente absoluta. En sus acciones el hombre va haciendo y realizando su vida personal, en virtud de ellas cobra su ser relativamente absoluto, pero lo cobra apoyado y fundado en la realidad ( $c$ fr. HD 76-92).

La realidad fundamento en cuanto última, posibilitante e impelente, domina y se apodera del hombre. Tal apoderamiento "implanta" al ser humano en la realidad. Y este apoderamiento "acontece" ligando al hombre al poder de lo real para que él sea relativamente absoluto. Esta peculiar "ligadura" es precisamente la religación (HD 92). La religación es un hecho constatable, radical y total en la misma realidad humana y tiene además carácter experiencial, manifestativo y problemático (cfr. HD 93-96).

Especial atención merece en este contexto la noción de voluntad de fundamentalidad ${ }^{4}$. Para su correcta comprensión, aquí se parte de la verdad como mera actualidad de lo real en la inteligencia, por tanto, como verdad real ( $c f r$. HD 246). La voluntad de verdad es, radicalmente, voluntad de verdad real. La verdad real es, ante todo y sobre todo, principio de todo proceso intelectivo (HD 247); y, por ello, "está siempre presente" en la intelección humana. Es la realidad en su verdad la que lanza al hombre a "idear". Al hacerlo, abre el campo de dos "posibilidades": "reposar en las ideas en y por sí mismas" o "dirigirse a la realidad misma". Entre esas dos posibilidades el hombre tiene que optar, es

13. Sobre este esta noción pueden verse D. Gracia, Voluntad de verdad. Para leer a Zubiri, Barcelona, 1986, pp. 211-236; I. Ellacuría, "La religación, actitud radical del hombre" (Apuntes para un estudio de la antropología de Zubiri)", Asclepio 16 (1996) 97-155. Reproducido varios años después en I. Ellacuría, Escritos teológicos I, ed. A. Estela Sánchez, San Salvador, 2000, pp. 39-105.

14. Una explicación más amplia en HD 246-258. En este contexto vale la pena tener presente el artículo de I. Ellacuría: "Voluntad de fundamentalidad y voluntad de verdad: conocimiento-fe y su configuración histórica", Revista Latinoamericana de Teología 8 (1986) 113-131. Reproducido en I. Ellacuría, Escritos teológicos I, ed. A. Estela Sánchez, San Salvador, 2000, pp. 107-137. 
decir, tiene que realizar un "acto de voluntad". Es precisamente la voluntad de verdad, y si ésta opta, no por las ideas, sino por la realidad, entonces tenemos la voluntad de verdad real (HD 248) ${ }^{15}$.

Ahora bien, al entregarse el hombre a la verdad real acontece la realidad y se realiza su ser. Entonces, la voluntad de verdad es voluntad de fundamentalidad En consecuencia, el ser del hombre es ser en verdad. Esto significa que todo su ser "lo es en y por la verdad de una realidad" que es "para" él. Entregarse a la realidad-fundamento significa apropiarse su "fundamentalidad". Es hacer que la fundamentalidad pase a formar parte de la estructura radical de su vida (HD 255).

Naturalmente, la opción por la fundamentalidad es siempre una opción libre, tanto para entregarse como para no entregarse. Pero al mismo tiempo en la voluntad de fundamentalidad también se pone de manifiesto su momento intelectivo. La intelección y la libertad de opción tienen en definitiva esta interna unidad: "es voluntad de fundamentalidad" (HD 257).

Hasta aquí hemos presentado, muy brevemente, las nociones de inteligencia sentiente y actualidad, sustantividad y verdad real, y religación y voluntad de fundamentalidad. Ellas nos introducen en la cuestión central de nuestro artículo: el agnosticismo, la indiferencia y el ateísmo.

\section{Planteamiento del problema}

El contexto más amplio en el que se ubican las siguientes reflexiones de Zubiri sobre el agnosticismo, la indiferencia y el ateísmo, es precisamente el de la voluntad de verdad, y por lo tanto el de la voluntad de fundamentalidad. Pero hemos de advertir al mismo tiempo que tales actitudes son aquí expuestas desde la perspectiva concreta de la disociación que de hecho se da en algunos seres humanos entre inteligencia y fe (cfr. HD 263-264) ${ }^{16}$.

La problematicidad de la justificación de la realidad de Dios se pone de relieve en tres hechos fundamentales. En el primero vemos que la "justificación intelectiva de la realidad de Dios ha sido múltiple". En efecto, son muchas las

15. En este contexto puede verse D. Gracia, Voluntad de Verdad. Para leer a Zubiri, Barcelona, 1986, pp. 237-251.

16. A mi juicio, una buena parte de la humanidad se caracteriza en nuestros días por seguir, en su vida diaria concreta, alguna de estas tres actitudes. Pero al mismo tiempo pienso que no todo aquel que sigue alguna de estas actitudes tiene claridad en su opción y tampoco en su intelección. Sin embargo, esto no significa que en ellos no haya opción ni intelección de la realidad-fundamento $\mathrm{y}$, por tanto, de la realidad misma de Dios. Todo ser humano tiene voluntad de fundamentalidad. ¿Cómo esa voluntad de fundamentalidad es expresada y vivida por cada hombre y mujer de hoy en su realidad concreta? He aquí una cuestión fundamental que teologalmente vale la pena plantearse y, por tanto, explicar y justificar. 
pruebas que se han dado de la existencia de la realidad de Dios. Pero además, se han intentado dar "nuevas" pruebas de su existencia, precisamente porque las anteriores no eran "satisfactorias"17. El segundo hecho concreto se pone de manifiesto en que existen muchísimas personas que se "despreocupan" del problema de Dios. En el ámbito de la opción constitutiva esta actitud se revela como "indiferencia". Finalmente también está el hecho de que muchas personas jamás han sentido a Dios como problema. En este caso, pareciera que la voluntad de fundamentalidad no es algo constitutivo de la realidad humana (HD 267).

El primer hecho expuesto se refiere esencialmente al "proceso intelectivo" que la voluntad de fundamentalidad pone en marcha. En cambio, el segundo y el tercero se refieren a la voluntad de fundamentalidad en su aspecto de la "opción" que en ella se realiza (HD 267).

Pues bien, en estos tres hechos expuestos queda planteado de modo adecuado el problema de la voluntad de verdad en la realidad humana. Analicemos separadamente cada uno de ellos para presentar finalmente su unidad problemática ( $c f$. HD 267-268). Comencemos por el primero.

\section{Intelección, agnosticismo y voluntad de buscar}

Respeto al primer hecho, el filósofo vasco constata y argumenta al mismo tiempo que no existe una admisión universal de las pruebas racionales que de la existencia de Dios se han dado hasta ahora, ni tan siquiera por parte de aquellas personas que admiten la realidad de Dios. Esto pondría de manifiesto la poca o ninguna importancia de la voluntad de verdad en relación al conocimiento demostrativo de Dios. Por tal razón, el momento intelectivo de la voluntad de verdad quedaría "refutado" (HD 268). Veamos cómo el filósofo resuelve esta cuestión.

\subsection{Disipación de un equívoco}

En opinión de Zubiri, la anterior afirmación encierra un grave equívoco que él ve necesario resolver. Dice efectivamente que la intelección demostrativa de la realidad de Dios, tiene un alcance y un valor que solamente dependen de la inteligencia. Esto no depende de la voluntad de verdad. En efecto, nota que la "discusión acerca de la validez de las pruebas es asunto de intelección y nada más". Evidentemente, que la voluntad de fundamentalidad pone en marcha el proceso intelectivo como algo inherente a esa voluntad es indiscutible. Ahora bien, lo que "no está dicho es que proceso intelectivo sea idéntico a demostración". Este es justo el "equívoco que hay que disipar". Y es que, según Zubiri, demostración es tan sólo un modo de intelección (HD 268).

17. A mi modo de ver, la multiplicidad y la novedad de las pruebas sobre Dios revela la problematicidad misma de la cuestión de Dios. 
Sin embargo, este modo de intelección no se identifica con el "proceso intelectivo, sino que este proceso es anterior, incluso cronológicamente, a toda posible demostración". Ciertamente, Zubiri tiene presente que la "demostración es la forma más rigurosa que este proceso puede llegar a revestir". Justo por eso puede afirmarse que la "discusión sobre el rigor del raciocinio no afecta a la existencia del proceso intelectivo. Es siempre una discusión dentro ya de este proceso" (HD 269).

En consecuencia, en el proceso intelectivo hay que considerar dos momentos. E1 primero, "aquello que la inteligencia logra inteligir procesualmente". E1 segundo es aquel momento "según el cual el proceso intelectivo está anclado en la voluntad de verdad". Pues bien, Zubiri clarifica que la "demostración" solamente concierne al primer momento "pero deja en pie el segundo que es el anterior y radical". Por tanto, "la multiplicidad y posible insatisfactoriedad de las pruebas no "refuta" en manera alguna el que haya una voluntad de verdad a la que esencialmente pertenece el proceso intelectivo" (HD 269).

Sin embargo, siendo distintos, estos dos momentos mantienen para Zubiri la unidad de ser un proceso. En este proceso, el ser relativamente absoluto del hombre en su realización necesita del fundamento en la problematicidad del poder de lo real. Es el problema de la vida real del ser humano. En este problematismo el hombre está lanzado físicamente "hacia" el ámbito de la fundamentalidad. "Y en esta apertura 'hacia' va incursa la inteligencia". Con lo cual, la intelección tiene un doble aspecto (HD 269).

Desde el primer aspecto, Zubiri afirma que la intelección "dibuja en el lanzamiento la figura de lo que sea la fundamentalidad", en nuestro caso se trata de Dios. Pero además, añade que ese ámbito es un "ámbito como momento de la realidad del poder de lo real". Y en este aspecto se pone de relieve el área de la "fundamentalidad". Esto es la estructura de la constitución de nuestro ser relativamente absoluto "en la realidad a cuyo poder estamos religados". Es una estructura propiamente intelectiva: es la intelección del "ámbito de la fundamentalidad de lo real". Evidentemente, esto es algo impreciso, "es la indeterminación de un ámbito real". Precisamente por esto, la voluntad de fundamentalidad "mueve a la inteligencia a precisarlo". He aquí el proceso intelectivo. Por tanto, Zubiri afirma que a la voluntad de fundamentalidad le pertenece "un proceso intelectivo que intelige un momento de la realidad en que se está realizando procesualmente" (HD 270).

Este proceso es efectivamente, en opinión de Zubiri, "un proceso de la inteligencia en la realidad, en ese modo de ésta que es 'realidad en hacia'" (HD 270). Dentro del ámbito "real en la realidad, el proceso intelectivo puede adoptar la figura de un razonamiento concluyente: es la prueba o demostración de que ese ámbito real ésta constituido por una realidad absolutamente absoluta" (HD 270- 
271). La demostración de esa realidad es sobre todo el "descubrimiento de la estructura misma de lo real en cuanto real 'en hacia', de esa realidad en la que ya estamos y que estamos ya inteligiendo". Pues bien, nuestro autor concluye afirmando que "toda demostración de la existencia de Dios es así proceso intelectivo dentro de la realidad misma" (HD 271).

Pero a continuación el filósofo advierte que no todo proceso intelectivo es necesariamente demostración. Y no lo es, ante todo, porque la "validez de las pruebas es siempre discutible". Pero desde la perspectiva de la voluntad de fundamentalidad, el proceso intelectivo es un hecho. Además, porque puede suceder que no se llegue a ninguna prueba que sea "convincente". Pero intelección de lo real siempre hay. Finalmente, y como muy bien destaca Zubiri, porque el "proceso intelectivo puede conducir a algo muy distinto a una demostración” (HD 271).

Puede suceder efectivamente que en el ser humano no exista una estricta justificación demostrativa de la realidad de Dios. Sin embargo, su admisión más o menos espontánea de la realidad de Dios es una auténtica fe. Aquí hay intelección de Dios pero ciertamente no termina en demostración (cfr. HD 271). Es lo que de hecho sucede con la mayor parte de los hombres creyentes que tienen fe en Dios y, sin embargo, jamás llegan a una justificación racional de la existencia de Dios. Hay fe, pero sin demostración. En opinión de Zubiri descubrir a Dios "no significa demostrar su existencia". De modo recíproco puede afirmarse que "demostrar la existencia de Dios no significa que el razonamiento sea 'el' camino para descubrir a Dios" (HD 272).

Pero puede suceder también que el ser humano en su proceso intelectivo "suspenda" la fe. Es justo el caso del agnosticismo (HD 272). ¿En qué consiste la actitud del agnóstico? ${ }^{18}$. Es lo que veremos a continuación.

\subsection{Agnosticismo y suspensión de la fe $\mathrm{e}^{19}$}

El agnosticismo consiste, en primer lugar, en asentarse en la ignorancia de Dios. La expresión característica del agnóstico sería: "no sé si existe"zo. En la medida en que sea ignorancia, "el agnosticismo es eo ipso un modo de proceso intelectivo". Lo es porque, según nuestro autor, ignorancia no significa carecer

18. En este contexto puede verse también B. Groth, "Agnosticismo", DTF 41-43; Gómez Caffarena, "La lección de un agnóstico: Enrique Tierno Galván", Sal Terrae 74 (1986) 195-203; J. I. González Faus, Proyecto de hermano. Visión creyente del hombre, Bilbao, $1987^{2}$, pp. 104-108.

19. Cfr. J. L. Cabria Ortega, Relación Teología-Filosofía en el pensamiento de Xavier Zubri, pp. 475-476; C. Díaz, "Agnosticismo", DTDC 11-14; J. I. González Faus y A. García-Santesmases, Elogio del agnosticismo, Barcelona, 2000, pp. 1-31.

20. Sobre tal expresión véase también J. L. Ruiz de la Peña, Crisis y apología de la fe. Evangelio y muevo milenio, Santander, 1995, p. 71. 
de un saber. En efecto, toda ignorancia es ignorancia de "algo". En otras palabras, la persona que ignora de alguna manera sabe "qué es lo que ignora". Por eso no se trata de "carencia" pues en la ignorancia hay algo que se ignora, se ignora precisamente "eso". Sin este "eso" no hay ignorancia sino "carencia" (HD 272) 21.

En segundo lugar, Zubiri precisa afirmando que en el agnosticismo se trata de "ignorancia de algo que es ignorado porque intelectivamente no se ha encontrado". Solamente esta ignorancia es la "propia del agnóstico". Es la ignorancia de lo no encontrado en la realidad por ser indeterminado. Sin embargo, es un momento de lo real que está siendo inteligido como indeterminado. Y es que en la interpretación del filósofo vasco el "ámbito de la fundamentalidad es un momento de la realidad". Por tanto, añade, "aunque no esté determinadamente conocido como siendo Dios, es sin embargo un momento de lo real". En otras palabras "está inteligido como siendo realmente aquello que aún no conocemos lo que en realidad es, pero que el agnóstico intelige que es real de un modo no bien conocido" (HD 273).

Desde el anterior punto de vista se entiende, por tanto, por qué para Zubiri el "agnosticismo no es del todo ajeno a la realidad de Dios ni a su intelección". Efectivamente, el agnosticismo es más bien ajeno al conocimiento riguroso de Dios. Es que inteligir una realidad no es sinónimo de conocerla. Por ejemplo, oír un sonido no significa conocer lo que en rigor el sonido es. La ignorancia del agnóstico es propiamente ignorancia e "incognoscibilidad" de la realidad de Dios. Por tanto, en la perspectiva de Zubiri el agnóstico tiene intelección de Dios aunque no tenga estricto conocimiento de Dios. En este sentido se trata precisamente de la incognoscibilidad de Dios (HD 273).

Finalmente, Zubiri precisa todavía un poco más tal actitud afirmando que se trata de la ignorancia y la incognoscibilidad de algo que el agnóstico "busca pero no encuentra" (HD 273). Ciertamente "se busca a Dios, porque Dios, aunque incógnito, es algo en que el agnóstico vive como palpando su nuda realidad" (HD 273-274) 22 .

21. Cfr. IRE 232 .

22. En un sentido muy amplio, y sin entrar en detalles exegéticos del texto, podemos afirmar que es precisamente lo que aparece en el discurso de Pablo a los atenienses, según Hch 17, 22-24: "Pablo, de pie en medio del Areópago dijo: 'Atenienses, veo que vosotros sois, por todos los conceptos, los más respetuosos de la divinidad. Pues al pasar y contemplar vuestros monumentos sagrados, he encontrado también un altar en el que estaba grabada esta inscripción: «Al Dios desconocido». Pues bien, lo que adoráis sin conocer, eso os vengo yo a anunciar" ". En su valoración teológica del agnosticismo B. Groth destaca, entras cosas, lo siguiente: "Realmente, en contra de una condena precipitada del agnosticismo hablan dos convicciones teológicas propias del cristianismo". La primera convicción afirma que "todo saber humano es "imperfecto" (cfr. 1Cor 13, 9), limitado y falible". Y, la segunda convicción teológica propia del 
Es que como muy bien dice nuestro autor, el agnóstico, como todo ser humano, también "palpa". Se trata de un tanteo pero "sin encuentro preciso" 23. Por tanto, desde este punto de vista el agnosticismo es "frustración de búsqueda intelectiva". Pues bien, es en esta frustración en donde en opinión del filósofo vasco "cobran su figura la incognoscibilidad y la ignorancia de Dios". Es en ella en donde justamente acontece la "suspensión de la fe" (HD 274) ${ }^{24}$.

En resumen, puede decirse que ya sea como ignorancia, como incognoscibilidad o como frustración, en el agnosticismo se pone de manifiesto un estricto proceso intelectivo ( $c f r$. HD 274).

\subsection{Agnosticismo y voluntad de buscar}

Cabe llamar la atención en este momento de la exposición que lo fundamental en este primer hecho expuesto radica en que, tanto desde la perspectiva de la fe intelectivamente "insuficiente" como desde el punto de vista del agnosticismo, cobra luz un aspecto esencial. Efectivamente, a la voluntad de fundamentalidad compete de modo constitutivo un proceso intelectivo (HD 274).

En este primer hecho se pone de manifiesto que la voluntad de fundamentalidad es esencialmente voluntad de buscar. En ella se unifican intelección y opción. En este contexto Zubiri dice que "la misma suspensión de fe del agnóstico es un modo positivo de opción". Por tanto, la voluntad de fundamentalidad también "se despliega en búsqueda intelectiva y en opción" ( cfr. HD 274).

Sin embargo, es necesario clarificar que la voluntad de buscar a Dios no es característica de todo ser humano. Esto mismo lleva a Zubiri a centrarse a continuación en el análisis del momento optativo de la voluntad de fundamentalidad. En él se inscriben los dos siguientes hechos por considerar ( $c f r$ HD 274).

cristianismo se refiere a "la doctrina tradicional sobre la 'incognoscibilidad de Dios" (cfr. 1.Jn 1, 18; ; Heb 11, 27; Rom 1, 20; Col 1, 15; 1Tim 1, 17; etc.), basada en la expresión bíblica del 'Dios desconocido' ( $c$ fr. Is 45, 15), tal como la defendieron teológicamente los capadocios (Basilio y Gregorio de Nisa, en controversia con el arriano Eunomio). Naturalmente, no se trata de dos cosas completamente distintas, sino que ambos problemas se relacionan íntimamente", B. Groth, "Agnosticismo", DTF 42.

23. En este contexto podemos citar lo que dice un conocedor de Zubiri: "La marcha "hacia' el fundamento es 'problemática'. En el Areópago San Pablo afirma que a Dios se le busca 'a tientas' (Hech 17, 27). El tanteo es, dice Zubiri, una de las formas de 'probación' física de realidad, el constitutivo formal de la 'experiencia'”, D. Gracia,

"El tema de Dios en la filosofia de Zubiri", Estudios Eclesiásticos 56 (1981) 76.

24. Estas cursivas son nuestras. 


\section{Indiferencia, despreocupación y voluntad de vivir ${ }^{25}$}

La constatación de la que aquí se parte consiste en afirmar que es un hecho innegable que muchas personas viven "despreocupadas" del problema de Dios. No olvidemos en este contexto que el ser humano puede ir "hacia" la realidad de Dios, optando entre Dios como realidad-objeto y Dios como realidad-fundamento. Pero es también un hecho evidente que muchas personas se "desentienden de toda opción". Se trataría de personas que ni están inscritas en un "proceso intelectivo hacia Dios ni llevan a cabo una opción respecto de Él”. Los dos momentos esenciales de la voluntad de fundamentalidad. Consecuentemente, "estas vidas desentendidas del problema de su fundamento, son eo ipso vidas sin voluntad de fundamentalidad". Zubiri advierte que no se trata sin más de "frivolidad" sino de una actitud humana seria ${ }^{26}$. Precisamente al asumirla con seriedad es cuando nos revela su propio carácter. ¿Qué significa, pues, la actitud de "entenderse"? (HD 275).

\subsection{Indiferencia intelectiva $a^{27}$}

El hombre en su proceso intelectivo se encuentra con el ámbito de la funda mentalidad. Llega un momento en que la inteligencia examina la naturaleza de ese ámbito y descubre la diferencia entre realidad-objeto y realidad-fundamento. Es entonces cuando la intelección "demuestra que ese ámbito es real por una realidad-fundamento" (HD 276).

Pero Zubiri advierte a continuación que aunque la inteligencia no llegase a descubrir ese ámbito de la fundamentalidad, siempre hay proceso intelectivo por estar lanzada "hacia" la fundamentalidad (HD 276). Sólo que en este caso el proceso intelectivo consiste en intelección in-diferente. El proceso intelectivo conduce a la actitud in-diferente. El que se desentiende es indiferente a la intelección de Dios como realidad-objeto y Dios como realidad-fundamento. Efectivamente, el indiferente "suspende la conclusión intelectiva" ${ }^{28}$. E1 indiferente no se hace cuestión de Dios. La actitud del indiferente se pone de manifiesto en la siguiente expresión: "que Dios sea lo que fuere" (HD 277).

25. A este grupo de personas despreocupados e indiferentes "Zubiri les consagra una notoria atención, en las que no parece imposible percibir ecos de preocupaciones muy concretas", A. Torres Queiruga, "Inteligencia y Fe", Estudios Eclesiásticos, 64 (1989) 163.

26. Frivolidad para Zubiri es "falta de seriedad" (HD 279).

27. Cfr. J. L., Cabria Ortega, Relación Teología-Filosofía en el pensamiento de Xavier Zubiri, pp. 476-477. Sobre el tema de la indiferencia también puede verse J. Martín Velasco, "Indiferencia religiosa", en DTF 707-710. A Charron, "Causas de la indiferencia religiosa", en DTF 710-720.

28. No olvidemos, en cambio, que el agnóstico lo que "suspende" es la misma fe (HD 277). 
Justo en la expresión "sea lo que fuere" es donde Zubiri encuentra 1o fundamental de la "suspensión" del proceso intelectivo. Es una rigurosa intelección. En efecto, es una "estricta intelección de lo que es la fundamentalidad como ámbito momentual de la realidad: sería algo realmente indiferente". E1 rasgo esencial del indiferente radica en la "ociosidad de ocuparse de Dios", "sea lo que fuere", es decir, "sea un Dios ocioso o no lo sea". El ámbito de la fundamentalidad es inteligido efectivamente como un "sea lo que fuere". Pero como ese ámbito es un momento de la realidad, el "ser" de lo "que fuere" implica siempre "la realidad indiferenciada de Dios: es la intelección indiferenciada de un momento de su fundamentalidad" (HD 277).

Hay que concluir, pues, que el que se desentiende de Dios tiene una rigurosa intelección gracias a la cual intelige a Dios, pero como "sea lo que fuere". La indiferencia es un modo de proceso intelectivo pero sin demostración (HD 278).

\subsection{Despreocupación optativa y unidad de intelección y opción}

Pero hay que añadir inmediatamente que la in-diferencia intelectiva es al mismo tiempo, en el ámbito de la opción, des-preocupación. Naturalmente, ésta actitud no significa que se viva sin opción respecto de Dios. Hay que clarificar que despreocupación no significa falta de opción. La persona despreocupada "siente que tras su no-ocuparse está latiendo la sorda presencia de aquello de que no se preocupa; por tanto, está soterradamente dirigido hacia ello". La despreocupación es la estricta y rigurosa opción por "no ocuparse de aquello que "está ahî́ indiferentemente". Lo cual significa que "se opta por la indiferencia: es el momento del 'des'” (HD 278).

Los dos aspectos (intelección y opción) están íntimamente ligados. Efectivamente, la persona desentendida "se ocupa despreocupadamente de lo que intelige como indiferente". Pues bien, el desentendido de Dios tiene proceso intelectivo y opción. "El ámbito de la fundamentalidad es inteligido como in-diferente, y el hombre se apropia optativamente la posibilidad de vivir en indiferencia fundamental: es la despreocupación" (HD 278). Por tanto, a la "in-diferencia intelectiva, corresponde la des-preocupación optativa: la vida 'des' es la vida en “in"” (HD 279).

Indiferencia y des-preocupación son momentos de una sola actitud "respecto de la fundamentalidad de la vida". Por tanto, desentenderse del problema de Dios muestra una "voluntad de fundamentalidad". En su aparente negatividad esta actitud nos pone de manifiesto algo esencial de la voluntad de fundamentalidad. En efecto, como la versión "hacia" la fundamentalidad es algo inevitable, el desentenderse de esa fundamentalidad "es un positivo modo de vivir" (HD 279).

Como modo de vivir esta actitud tiene dos aspectos. En primer lugar, la persona desentendida de la fundamentalidad de la vida vive "abandonado" "a lo 
que fuere". En otras palabras, "se vive en una indiferencia fundamental". A este modo de vivir el filósofo vasco lo llama: "dejarse vivir"’9. Esto significa "dejarse fundamentar". No se trata de una actitud ligera o frívola. La persona que se desentiende de Dios "vive seriamente desde su fundamento". Por tanto, la voluntad de dejarse vivir es voluntad de fundamentalidad. Según Zubiri, es una especie de "entrega indiferente a la fundamentalidad de la vida". Es una fe "indiferente y despreocupada"30 (HD 279).

En segundo lugar, nuestro autor precisa un poco más notando que ciertamente se trata de un dejarse vivir, pero de un "dejarse" "sólo respecto de su fundamento". Y añade que "en sí misma esta actitud es una resuelta voluntad de vivir". Dicho con otras palabras, la persona despreocupada "vive dejándose vivir porque por encima de su indiferencia fundamental lo que hace es afirmar enérgicamente que vive y quiere vivir". Efectivamente, "su desentenderse del problema de Dios es una actitud tomada en aras de la vida". El hombre desentendido "opta por des-preocuparse de un Dios que intelige como indiferente, precisamente por su voluntad de vivir: quiere que la indiferencia de la realidad fundamental no sea un impedimento para la vida" (HD 280).

Pues bien, tanto el aspecto del "dejarse vivir" como el aspecto de la "voluntad de vivir", unitariamente considerados, definen lo que el filósofo vasco llama la penultimidad de la vida. La persona que se desentiende de la realidad de Dios vive "en la superficie de sí mismo". Es, en efecto, vida "penúltima". Lo cual muestra su propia limitación: la "indiferencia". Pero también muestra que la voluntad de fundamentalidad es algo concreto, es "voluntad de vivir". Con todo, hay en estas actitudes proceso intelectivo y opción. Ellos son "despliegue fundamental de la voluntad de vivir" (HD 280).

Sin embargo, no todo hombre tiene voluntad de vivir ya que existen muchas personas para quienes su voluntad de vivir más bien "reposa sobre sí misma" (HD 280). Es precisamente lo que tenemos que exponer a continuación.

29. En este contexto vale la pena proponer la siguiente insinuación del teólogo y filósofo gallego: "Si en la indiferencia resonaba la 'diferencia ontológica' de Heidegger, acaso no sea aventurado insinuar que en este 'dejarse vivir' hace eco la exaltación de la vida en Ortega y Gasset (profesor y amigo, su talante vitalista y su actitud ante la religión, tan diferentes de Zubiri, tuvieron por fuerza que darle mucho de que pensar a éste)", A. Torres Queiruga, "Inteligencia y fe”, Estudios Eclesiásticos, 64 (1989) 163-164.

30. Estas cursivas son nuestras. 


\section{Ateísmo y voluntad de $\operatorname{ser}^{31}$}

\subsection{Exposición del hecho del ateísmo}

Además de las personas despreocupadas e indiferentes, existe un tercer he cho en el que se aglutina un grupo de personas cuyo número va creciendo: es el ateísmo ${ }^{32}$. Tales personas ni tan siquiera se despreocupan de la cuestión de Dios porque para ellas Dios no significa problema alguno. Ciertamente es una vida que tienes sus propios problemas, pero se reducen a ser problemas "intra-vitales". Desde un punto de vista muy amplio, sin embargo, esta forma de vida no plantea ningún problema; la vida para estas personas "es lo que es y nada más". En efecto, es "la vida que reposa sobre sî misma". Es vida "atea". Según Zubiri, no se trata de un ateísmo que fuera "contra" Dios, esto no es lo fundamental del ateísmo. En efecto, "es cada día mayor el número de personas cuyo ateísmo no va contra nada ni contra nadie" (HD 281) ${ }^{33}$.

El ateísmo tampoco es despreocupación o agnosticismo. En el ateísmo se trata propiamente de la "vida vivida en y por sí misma "y nada más". Es efectivamente "vida a-tea en el sentido meramente privativo del prefijo 'a'". La apelación a otra realidad fundante que no fuera la vida pertenece al no-ateo. Y por eso se piensa que el ateísmo sería la actitud primaria o radical, "lo demás" es opcional. Por eso la creencia, el agnosticismo y la despreocupación tienen que justificarse. El ateísmo no. La conditio possidentis sería "el hecho de la vida atea" (HD 281).

31. Cfr. J. L. Cabria Ortega, Relación Filosofia-Teología en el pensamiento de Xavier Zubiri, pp. 477-480. Una aproximación teológico-trinitaria del ateísmo en J. José Sánchez, "Ateísmo", en DTDC 112-123.

32. Este grupo de los ateos "resulta mucho más conocido" para Zubiri, "precisamente porque es preocupación constante desde el principio de su reflexión. A diferencia de los primeros trabajos, Zubiri 'desmoraliza' ahora el problema y lo ve en su facticidad, digamos, 'secular'”, A. Torres Queiruga, "Inteligencia y fe", Estudios Eclesiásticos 64 (1989) 164. En este contexto puede verse también EPD, en NHD 448-454, I. Ellacuría, "Existencialismo ateo", en Dios-Ateísmo. Tercera semana de teología. Universidad de Deusto, Bilbao, 1968, pp. 191-212.

33. A mi modo de ver, esta precisión de Zubiri es de una clarificación singular. Ir "contra" Dios no es lo esencial del ateísmo. Este ir contra Dios se vuelve, muchas veces, un ir contra el teísta, y lleva a la falsa actitud de pedirle cuentas al teísta en el sentido de que sólo él tiene que justificar su fe. Lo cual es totalmente falso. También el ateo tiene que justificar su creencia. El problema de creer que el ir "contra" es lo esencial del ateísmo ha llevado a muchas personas a convertir el ateísmo en una mera moda. $\mathrm{Y}$, sobre todo, de algunos filósofos e intelectuales que se sienten bien en esta moda. Pero todas las modas pasan, son efímeras. 
Ahora bien, ¿es verdad que todo lo anteriormente expuesto es así? (cfr. HD 281). Veamos cómo responde Zubiri.

\subsection{Problematicidad e intelección de la facticidad del ateo}

En primer lugar y ante todo, Zubiri se pregunta "qué se entiende con precisión cuando se dice que la vida tomada en y por sí misma no es un problema" (HD 281-282).

Recordemos que se trata de la vida tomada en su totalidad. Este es el problema. Y la vida tomada en tal sentido es, según Zubiri, "la vida en cuanto es la constitución y construcción" del ser del hombre. La persona está "en la realidad". Las cosas reales configuran la vida del hombre y esta vida es la construcción del su ser. Por tanto, las cosas reales configuran el ser de la realidad del hombre precisamente por su "carácter de realidad". Este carácter de realidad es el poder de lo real que constituye "la fundamentalidad de mi vida". Por tanto, afirmar que se considera la vida en su globalidad consiste fundamentalmente "en decir que se toma la vida personal en religación". Este poder de lo real es interno a las cosas reales y es "enigmático". He aquí el problema. Y lo es para todo ser humano. Es un problema intrínseco a todo hombre el cual existe antes de que se formule como problema. Justo por esto, el hombre está inexorablemente lanzado a inteligir en qué consiste aquel poder. Es el origen de un proceso intelectivo (HD 282).

En segundo lugar, en el caso concreto que aquí exponemos, puede afirmarse que el ateísmo consiste propiamente en que intelige que "el poder de lo real en las cosas es un hecho y nada más que un hecho, sin necesidad de fundamento ulterior: es la pura facticidad del poder de lo real". Es efectivamente la "vida en y por sí misma" y, además, "la vida reposando sobre la pura facticidad del poder de lo real". Sobre esto Zubiri nota dos cosas. En la primera dice que es evidente con ello que existe en la persona atea proceso intelectivo sobre "totalidad de la vida" $y$, por tanto, la vida para el ateo es tan "problemática" como lo es para todo ser humano. Lo que sucede es que el ateo, quizás sin darse cuenta, soluciona este problema por la "vía de la pura facticidad" (HD 283).

El segundo aspecto que el filósofo señala es que "resolver el problema de la fundamentalidad de la vida con la pura facticidad significa [...] que la facticidad del poder de lo real es una interpretación". Y por lo mismo es necesario "dar razones". Ciertamente la persona que admite la realidad de Dios tiene que dar razones de su admisión. Pero igualmente cierto es que el ateo también tiene que dar razones de por qué concibe el poder de lo real como "pura facticidad". Zubiri insiste afirmando que el ateísmo no es la actitud primaria, la conditio possidentis, sobre la cual tendría que justificarse la actitud del teísta. "Teísmo y ateísmo son dos modos como concluye el proceso intelectivo respecto del poder de lo real". Y añade que la "facticidad del poder de lo real no 
es un puro factum sino una intelección, y como toda intelección está necesitada de fundamento" (HD 283).

Tal fundamento tiene que lograrse por la intelección. Por tanto, el ateísmo consiste en entender "la fundamentalidad de la vida como pura facticidad" (HD 284).

\subsection{Opción por la autosuficiencia de la vida}

En este mismo contexto, Zubiri añade que el ateo también "lleva a cabo una opción". Efectivamente, apropiarse voluntariamente la facticidad del poder de lo real es optar por la autosuficiencia de la vida. Autosuficiencia se entiende aquí en el "sentido etimológico de algo que se basta a sí mismo en su línea: una vida que es lo que es y como es y nada más". Por tanto, la autosuficiencia de la vida "es la opción por la facticidad del poder de lo real" (HD 284).

Y justo por ser opción "es entrega personal a la facticidad, es fe en la facticidad". El ateísmo es precisamente la "fe del ateo" 34 . En este contexto el filósofo recuerda que la fe "es entrega formal a una persona en cuanto verdadera" ${ }^{35}$. Pues bien, Zubiri afirma convencido que el ateo se entrega propiamente "a su propia realidad formal como única y suficiente realidad personal verdadera". Y añade que "en esta entrega a sí mismo como verdad consiste la fe del ateo. El ateo se entiende entregado a sí mismo y se acepta como tal". Por tanto, puede afirmarse que el ateo realiza una opción. Es que "el ateísmo no es menos opcional que el teísmo" (HD 284).

Por consiguiente, puede concluirse afirmando que también en el ateísmo hay intelección y opción. Ambos son momentos esenciales de la voluntad de fundamentalidad. Aquí también se pone en marcha la voluntad de fundamentalidad que efectivamente "se despliega en intelección del poder de lo real como pura facticidad", y también en "opción por la autosuficiencia de la vida personal". Por tanto, el ateísmo no es una excepción a todo lo que se viene exponiendo (HID 284).

\subsection{Voluntad de ser}

En este contexto, Zubiri da un paso más en su exposición y pone de manifiesto a continuación un aspecto positivo de la actitud "a-tea". Afirma que la voluntad de fundamentalidad del ateo pone de relieve un carácter esencial de toda voluntad de fundamentalidad (HD 284).

34. Estas cursivas son nuestras.

35. La definición precisa de Zubiri afirma que "la fe es formalmente una entrega o adhesión personal, firme y opcional a una realidad personal en cuanto verdadera" (HD 221). 
El filósofo destaca, en primer lugar, que la facticidad autosuficiente consiste en que el ateísmo es una voluntad de fundamentalidad que recae sobre el ser del hombre como modo de ser absoluto pero a su modo. En segundo lugar, subraya que el ateísmo es una voluntad de fundamentalidad que concierne al ser del hombre como algo "cobrado", "relativo" (HD 285).

Ambos aspectos subrayados en su unidad constituyen la voluntad de fundamentalidad del ateo como una "voluntad de ser relativamente absoluto". E1 ateísmo "es la interpretación del ser relativamente absoluto como facticidad autosuficiente" (HD 286).

Por tanto, el ateísmo pone de manifiesto que la voluntad de fundamentalidad es "voluntad de ser relativamente absoluto". En efecto, Zubiri dice que "para quererse como facticidad autosuficiente, hay que empezar por quererse como ser relativamente absoluto". En definitiva, la voluntad de fundamentalidad es voluntad de ser. Voluntad de ser relativamente absoluto (HD 286).

Una vez expuestos el agnosticismo y la voluntad de buscar, la despreocupación y la indiferencia y la voluntad de vivir, y el ateísmo y la voluntad de ser, veamos finalmente si estos tres hechos tienen alguna unidad.

\section{Voluntad de ser viviendo en búsqueda}

Recordemos que la voluntad de fundamentalidad es intrínseca a la persona y que se despliega en intelección y opción. En este contexto hemos considerado que tanto el agnosticismo, como la despreocupación y el ateísmo consisten en ser "proceso intelectivo y opción respecto del fundamento". En consecuencia, los tres hechos examinados poseen "verdadera" voluntad de fundamentalidad (HID 287).

Este examen también ha puesto al descubierto que la voluntad de fundamentalidad es principio originario de la constitución del ser del hombre. La voluntad de fundamentalidad como "principio de actitud" se mostró en tres hechos distintos. En el caso del agnosticismo es voluntad de buscar, en el caso del desentendido es voluntad de vivir, y en el caso del ateo es voluntad de ser. Por tanto, Zubiri afirma que como principio de actitud, la voluntad de fundamentalidad es "voluntad de ser, de vivir y de buscar" (HD 287).

Precisamente ahora es cuando el filósofo procede a "conceptuar unitariamente" estas tres características de la voluntad de fundamentalidad (HD 287).

\subsection{La unidad de los tres momentos}

En este momento de su exposición Zubiri se pregunta, “¿en qué consiste la unidad principial de estos tres momentos y por tanto la versión hacia la realidad de Dios?" (HD 287). 
En primer lugar, cabe recordar que en la perspectiva de nuestro autor el hombre es una realidad sustantiva viviente y personal. Esta realidad sustantiva tiene ser $^{36}$. Vivir consiste en la constitución de su ser de lo sustantivo. En esto consiste formalmente vivir. Este ser tiene dos dimensiones. La primera es "aquella según la cual el hombre 'es' una realidad que se posee a sí misma, que se pertenece a sî misma, que es 'suya'”. En esto consiste ser persona. El ser del hombre, entonces, es un ser personal. La segunda dimensión es aquella según la cual, “siendo” el hombre afirma su realidad como suya frente a todo lo real en cuanto real". En consecuencia, "pertenecerse a sí mismo es una pertenencia respecto de todo lo real: es una pertenencia absoluta”. Pues bien, el ser personal es un ser absoluto. Pero como este ser es algo cobrado, en rigor se trata de un ser "relativamente absoluto. Un ser personal relativamente absoluto". En esto consiste precisamente "ser Yo" (HD 288).

En segundo lugar, el hombre realiza su ser "apoyado en las cosas reales" y también en las demás personas, "asî como en sus propios caracteres individuales". Esto significa que el ser personal del hombre al estar con las cosas aquello en que está es en "la" realidad (HD 288). "La" realidad domina en el hombre con un poder y le determina su ser. Estar inevitablemente dominados por este poder de lo real es justo la religación. "Y 'la' realidad presente a mí en este poder religante constituye fundamentalidad de mi ser personal” (HID 289).

En tercer lugar, cuando me hago cargo de la realidad se me abren diversas posibilidades de respuesta. Al responder tengo que apropiarme una posibilidades entre otras, es la volición. Lo que la voluntad quiere es mi ser relativamente absoluto. Y mi ser relativamente absoluto me lleva, en definitiva, a "querer mi ser en verdad real". Efectivamente, toda voluntad según Zubiri "arranca de, se nutre con y aboca en mi verdad real". La voluntad de ser, pues, es voluntad de verdad. Por tanto, "mi ser relativamente absoluto envuelve en su entidad misma mi propia verdad real". En consecuencia, la voluntad de verdad real es "voluntad de ser relativamente absoluto viviendo desde la realidad y fundado en ella. Es radical y unitariamente voluntad de ser y de vivir" (HD 290).

Por tanto, el ser del hombre "determina su ser en una voluntad de verdad real". Esto significa que el ser del hombre es determinado por la presencia de la realidad como fundamento de su vida. Y esta actualización es precisamente 1o que constituye la realidad-fundamento. Su intelección significa la posibilidad de vivir fundadamente por la opción. Y apropiarse esta realidad significa entregar-

36. En opinión del filósofo vasco no hay ser sustantivo porque el ser no tiene sustantividad. Solo hay "ser de lo sustantivo" porque su fundamento último está en la realidad. Una importante clarificación sobre este importante tema y que corresponde a su etapa de madurez puede verse en la primera y segunda parte de su trilogía sobre la inteligencia sentiente, IRE 222, IL 352. 
se. En efecto, "entregarse a algo es apropiarse optativamente ese algo como posibilidad de mí mismo”. Volición, pues, es entrega (HD 290).

En cuarto lugar, el poder de lo real que me determina religadamente está en las cosas reales, pero hay que advertir que está sin identificarse con ninguna de ellas. Es "la" realidad como enigma (HD 290). Por eso, el hombre está religado a "la" realidad de un modo problemático. En las cosas reales el ser humano ha de tratar de estar en "la" realidad, por tanto, él tiene que "buscar en cada cosa [real] la realidad en que estar". De ahî que según Zubiri la "voluntad de ser relativamente absoluto viviendo, sea forzosamente voluntad de buscar". Voluntad de buscar la realidad para mí(HD 291).

Voluntad de buscar el fundamento del poder de lo real que me tiene religado y que me abre las posibilidades de optar para "ser viviendo". Según convicción expresa del filósofo "la fundamentalidad es un carácter de la realidad que me está dado en la religación y por tanto en la realidad misma, pero en la realidad 'en hacia'". El hombre tiene que buscar ese fundamento, y por tanto, dice Zubiri, la voluntad de verdad real es "voluntad de fundamentalidad". La voluntad de fundamentalidad no sólo es "voluntad de ser y de vivir sino también [voluntad] de buscar. Dicho en forma de síntesis: es voluntad de ser viviendo en búsqueda" (HD 291) . $^{37}$.

De esta manera quedan conceptuados estos tres momentos que son los que unitariamente constituyen, en opinión de Zubiri, la esencia de la voluntad de fundamentalidad (cfr. HD 292).

\subsection{Momentos de la voluntad de fundamentalidad}

La voluntad de fundamentalidad significa también entregarse a lo que la inteligencia haya logrado inteligir como fundamento. La voluntad de fundamentalidad es "radicalmente una voluntad que desde la raíz última de mi realidad, se despliega en ser viviendo y buscando una entrega, todo lo deficiente que se quiera, pero verdadera entrega". Es efectivamente una voluntad de situar "vital y firmemente mi ser en el poder de lo real" que transciende las cosas y mi persona. Es justo la transcendencia del hombre. Por eso, entregarse al fundamento de la persona significa, sobre todo, entregarse a su propia "transcendencia" (HD 292). De modo recíproco, "entregarse a la transcendencia de la persona es entregarse en la persona misma a su intrínseco y formal fundamento" (HD 292-293).

Esta entrega es justo la opción radical de la voluntad de fundamentalidad, la cual tiene dos aspectos. En primer lugar, el aspecto intelectivo. Aquí se trata de la puesta en marcha de la intelección hacia el fundamento al que el hombre está

37. Estas cursivas son nuestras porque a nuestro juicio en esa afirmación se expresan, a modo de tesis y en forma magistral, los tres hechos expuestos. 
lanzado. Por su proceso intelectivo la inteligencia puede llegar a distintos resultados: teísmo, agnosticismo, indiferencia, o la pura facticidad. Es competencia de la inteligencia decidirlo. Y lo decide justificando intelectivamente su opción. Toda persona sin excepción está obligada a dar razones o a "justificar intelectivamente el término de su intelección". Solo entonces la intelección de Dios es "conocimiento" de la realidad de Dios. Ninguna persona está exenta de la "necesidad de dar razones" (HD 293).

En segundo lugar, está el aspecto optativo. Éste consiste en que según sea el resultado del proceso intelectivo al cual se ha llegado, "la opción será la autosuficiencia de la facticidad, la despreocupación ante lo indiferente, o la entrega a 1a realidad de Dios"38. Lo fundamental en todo esto radica en que se trata de una opción "físicamente necesaria", y por lo mismo, es una opción que siempre está presente en el hombre. Y esto por dos razones. Ante todo, por su carácter de realidad-fundamento y, además, porque en la voluntad de fundamentalidad se trata de un "querer" en el que la persona se juega su propio ser relativamente absoluto. E1 teísmo, el agnosticismo, la despreocupación o el ateísmo son, efectivamente, "modos" en los que se expresa la voluntad de fundamentalidad (HD 294).

Por tanto, la voluntad de fundamentalidad es el principio originario de la vida personal del hombre en cuanto constitución de su ser. Esta actitud es, en definitiva, la que se "despliega en intelección y opción" (HD 294).

De esta manera quedan expuestos el agnosticismo, la indiferencia y el ateísmo. Tales hechos encuentran su raíz y unidad en la voluntad de fundamentalidad (cfr. HD 295).

\section{Conclusión}

En el artículo pretendíamos mostrar que tanto el agnosticismo, como la indiferencia y el ateísmo son actitudes fundamentales del ser humano en las que se manifiesta la voluntad de fundamentalidad.

En este contexto expusimos que la inteligencia humana es "inteligencia sentiente". Y que la esencia de la intelección es la "actualidad". Ambas nociones manifiestan que la inteligencia sentiente es formalidad del "de suyo". Pero el "de suyo" también es sustantividad, y ésta tiene ser, es el ser de lo sustantivo. La ratificación del "de suyo" es verdad real (IRE 233). Ahora bien, la realidad fundamento domina y se apodera del hombre. Ese apoderamiento "acontece" ligando al hombre al poder de lo real para que él sea relativamente absoluto. Esta particular ligadura es la religación (HD 92). Cuando el hombre se entrega a la verdad real acontece la realidad y se realiza su ser. Entonces, la voluntad de verdad es voluntad de fundamentalidad (HD 255).

38. En este contexto no hay que olvidar la opción de la suspensión de la fe por parte del agnóstico que busca pero no logra un conocimiento pleno de Dios ( cfr. HD 272). 
Una preocupación fundamental que merece la pena recoger del pensamiento de Zubiri es el haber tratado el tema de la realidad de Dios como un verdadero "problema"39. El problema de Dios, y por consiguiente el de la entrega del hombre a Dios, es una cuestión inexorable que compete a todo ser humano sin excepción. Dios es un problema intrínseco al hombre. Ciertamente lo es del teísta, pero también lo es del agnóstico, del indiferente y del ateo. Y por lo mismo, no es exclusivo del teísta dar razón de su fe. Es también competencia del agnóstico, del indiferente y del ateo explicar y fundamentar por qué cree en aquello que cree.

Ahora bien, el contexto real en el que aparecen las reflexiones sobre el agnosticismo, la indiferencia y el ateísmo es el de la disociación entre inteligencia y fe.

En ese contexto mostramos, ante todo, que el agnóstico no sabe si Dios existe. Para él se trata de "ignorancia de algo que es ignorado porque intelectivamente no se ha encontrado". Aquí lo real es inteligido como algo indeterminado. En rigor se trata de ignorancia y de incognoscibilidad de algo que el agnóstico busca (a Dios) pero que no logra encontrar (HD 273). Por eso se frustra su búsqueda intelectiva. En ella acontece precisamente la "suspensión de la fe". Ambos aspectos manifiestan la voluntad de fundamentalidad en su momento de voluntad de buscar (HD 274).

Además vimos que cuando la inteligencia no logra descubrir el ámbito de la fundamentalidad, el proceso intelectivo conduce a la actitud in diferente. Ésta no se hace problema de Dios. Aquí aparece la "suspensión" del proceso intelectivo. La indiferencia es un modo de proceso intelectivo pero sin demostración. A la in-indiferencia intelectiva corresponde la despreocupación. Ésta es la opción de "no ocuparse de aquello que "está ahî́ indiferentemente" (HD 278). Indiferencia y despreocupación son momentos de una sola actitud "respecto de la fundamentalidad de la vida". En definitiva se trata de "entrega indiferente a la fundamentalidad de la vida". Es efectivamente una fe "indiferente y despreocupada" (HD 279). Pero la actitud del despreocupado es una decidida voluntad de vivir. En efecto, el despreocupado "vive y quiere vivir" (IID 280). Y la voluntad de vivir es un componente de la voluntad de fundamentalidad.

39. Una constatación que fundamenta esta conclusión se encuentra en D. Gracia, según el cual "la práctica totalidad de los trabajos dedicados por Zubiri al estudio del acceso del hombre a Dios llevan en su título la palabra 'problema': 'En torno al problema de Dios' (1935), ‘El problema de Dios' (1948-49), 'Introducción al problema de Dios' (1963), 'El problema filosófico de la historia de las religiones' (1965), 'El problema de Dios en la historia de las religiones' (1965), 'El hombre y el problema de Dios' (1968), "El problema teologal del hombre’ (1975)”. A continuación, Gracia concluye afirmando que "tras esta enumeración no puede caber la menor duda de que, según Zubiri, Dios es un 'problema' para el hombre, y que, además, es un problema 'filosófico"”, D. Gracia, "El tema de Dios en la filosofia de Zubiri”, Estudios Eclesiásticos $56(1981) 68$. 
También mostramos que el ateo intelige el poder de lo real como pura facticidad. Y esto es una interpretación, lo cual significa que el ateo tiene que dar razones de tal intelección (HD 283). Esto significa además que el ateo opta por la autosuficiencia de la vida: "es la opción por la facticidad del poder de lo real". Y por ser opción "es entrega personal a la facticidad, es fe en la facticidad". El ateísmo es la "fe del ateo". En efecto, él se entrega "a su propia realidad formal como única y suficiente realidad personal verdadera". En consecuencia también en esta actitud hay opción e intelección (HD 284). La voluntad de fundamentalidad del ateo pone de manifiesto la "voluntad de ser relativamente absoluto". Por tanto, la voluntad de fundamentalidad es en el ateo voluntad de ser (HD 286).

En definitiva, la unidad de esas tres actitudes consiste en que la voluntad de fundamentalidad es voluntad de ser viviendo en búsqueda (HD 291). Tales momentos expresados en esa síntesis constituyen la esencia de la voluntad de fundamentalidad ( $c f r$. HD 292). Por tanto, el agnosticismo, la indiferencia y el ateísmo ponen de manifiesto un modo de expresar la voluntad de fundamentalidad en su momento optativo e intelectivo. Ellos son modos concretos de justificar el entregarse, todo lo limitado que se quiera, pero en definitiva modos de entrega: como suspensión de la fe, como entrega indiferente o como entrega a la pura facticidad ( $c f r$. HD 295).

A mi modo de ver, es un mérito indiscutible de Zubiri el haber sabido diferenciar lo característico del agnóstico, del indiferente y del ateo, y al mismo tiempo radicarlos en la voluntad de fundamentalidad. En todo ello ha jugado un papel fundamental e indiscutible su teoría de la inteligencia humana como inteligencia sentiente constitutivamente abierta a la realidad de Dios.

\section{Siglas usadas de las obras de $\mathrm{X}$. Zubiri}

EPD "En torno al problema de Dios", en NDH 417-454.

HD Hombre y Dios, Madrid, $1998^{6}$.

IL Inteligencia y logos, Madrid, 1982.

IRA Inteligencia y razón, Madrid, 1983.

IRE Inteligencia sentiente. Inteligencia y Realidad, Madrid, $1991^{4}$.

NHD Naturaleza, Historia, Dios, Madrid, 199911.

\section{Otras siglas usadas}

DTF Diccionario de Teología Fundamental, ed., R. Latourelle-R. Fisichella-S. Pié-Ninot, Madrid, 1992.

DTDC Diccionario Teológico. El Dios cristiano, ed., X. Pikaza y N. Silanes, Salamanca, 1992. 